\title{
Representações Sociais, Saúde Mental e Imigração Internacional
}

\author{
Representaciones Sociales, \\ Salud Mental Y Migración Internacional \\ Social Representations Mental Health \\ And International Migration
}

leda Franken, Maria da

Penha de Lima Coutinho

Universidade

Federal da Paraíba

Maria Natália Pereira

Ramos

Universidade

Aberta de Lisboa

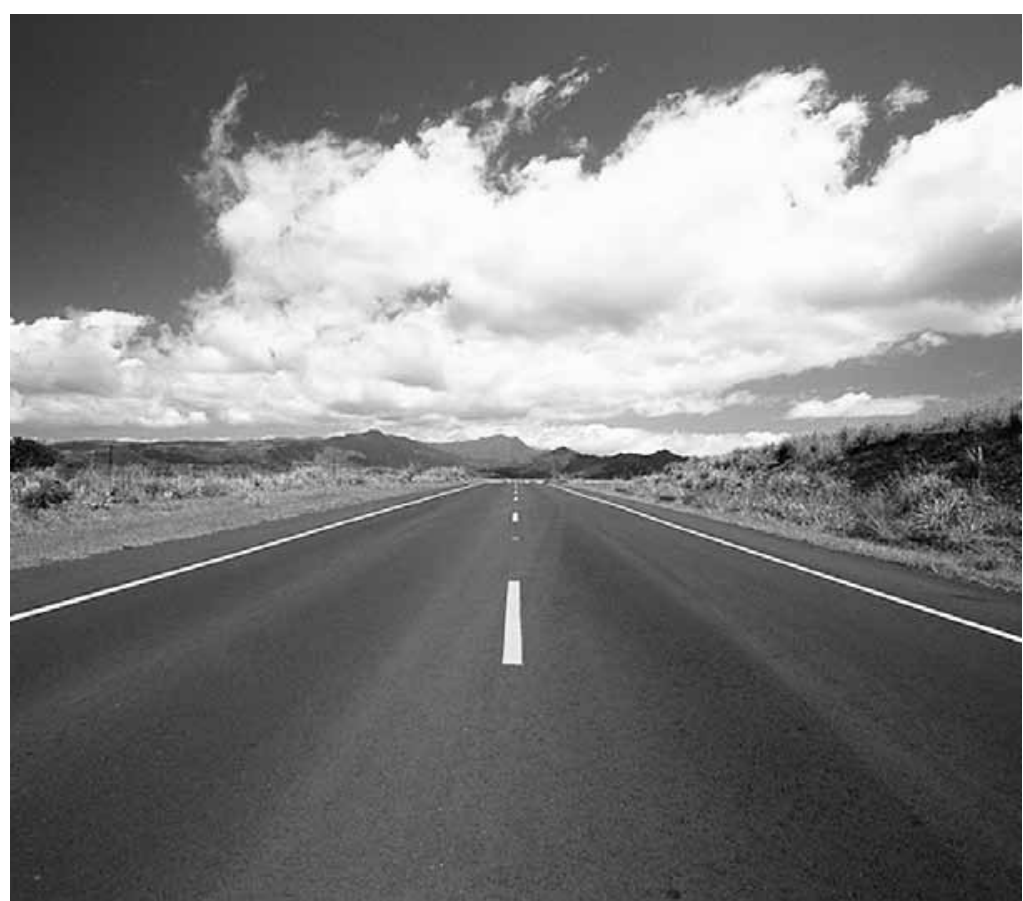


Resumo: O movimento de populações, de pessoas mais ou menos organizadas, é fenômenos tão antigos como a humanidade, mas a migração de milhões de pessoas, nos dias de hoje, está se convertendo em um processo com níveis de estresse tão intensos que superam a sua capacidade de adaptação. Este estudo objetiva avaliar a saúde mental e analisar as representações sociais sobre os construtos imigração, imigrante, saúde mental e futuro de imigrantes brasileiros residentes na cidade de Genebra/Suíça. O estudo é exploratório e trabalha com abordagem multimétodo, com uma amostra de 266 participantes submetidos ao questionário biosociodemográfico, ao instrumento de Scrining Self-Reporting Questionnaire e à entrevista semidirigida. Os dados dos questionários foram analisados através do pacote estatístico Statistical Package for the Social Sciences (SPSS.for Windows.16), utilizando-se a estatística descritiva e inferencial e os conteúdos das entrevistas pela análise de conteúdo de Bardin (1997/2002). Os resultados demonstraram que a variável tempo de imigração favoreceu o aparecimento de déficits na saúde mental dos participantes. O presente estudo permitiu concluir que, nesse contexto de imigrações internacionais, as representações sociais dos imigrantes e a sua saúde mental são influenciadas, proporcionalmente, pela duração ou pelo tempo da imigração.

Palavras-chave: Representações sociais. Imigração humana. Saúde mental. Distúrbios mentais.

Abstract: The population movements of people who are more or less organized are a phenomenon as old as humanity. But the migration of millions of people who immigrate today is becoming a process with so intense stress levels that exceeds their capacity of adaptation. This study aims to assess the mental health and analyze the social representation of the constructs immigration, immigrant, mental health and the future of Brazilian immigrants who live in the city of Geneva, Switzerland. This is an exploratory multimethod approach held with a sample of 266 participants who answered the bio-social demographic questionnaire, the Instrument for Self-Reporting Questionnaire Scrining and the semi-directed interview. The questionnaire data were analyzed using the Statistical Package for Social Sciences (SPSS.for Windows.16), using descriptive and inferential statistics and the content of the interviews through the analysis of Bardin (1997/2002). The results showed that the variable time of immigration has favored the emergence of deficits in the mental health of participants. This study concluded that in this context of international immigration the social representations and the mental health of the immigrants are influenced by the duration or by the time of immigration.

Keywords: Social representation. Imigration. Mental health. Mental disorders.

Resumen: Los movimientos de poblaciones, de persona más o menos organizada son un fenómeno tan antiguo como la humanidad. Pero, para que millones de personas inmigren en los días de hoy, está convirtiéndose en un proceso con niveles de estrés tan intensos que superan su capacidad de adaptación. Este estudio objetiva evaluar la salud mental y analizar las representaciones sociales sobre los constructos inmigración, inmigrante, salud mental y futuro de inmigrantes brasileños residentes en la ciudad de Ginebra/ Suiza. Se trata de un estudio exploratorio trabajando con abordaje multimétodo, con una muestra de 266 participantes sometidos al cuestionario bio-socio-demográfico, al instrumento de Scrining Self-Reporting Questionnarie y a la entrevista semidirigida. Los datos de los cuestionarios fueron analizados a través del conjunto estadístico Statistical Package for the Social Sciences, (SPSS.for Windows.16), siendo utilizada la estadística descriptiva y de inferencia y los contenidos de las entrevistas por el análisis de contenido de Bardin (1997/2002). Los resultados demostraron que la variable tiempo de inmigración favorecieron el aparecimiento de déficits en la salud mental de los participantes. El presente estudio permitió concluir que, en este contexto de inmigraciones internacionales, las representaciones sociales de los inmigrantes, y su salud mental son influenciadas, proporcionalmente, a la duración o al tiempo de la inmigración.

Palabras clave: Representaciones Sociales. Imigración. Salud Mental. Trastornos Mentales .

Agradecemos a Mme. Sophie Frezza, diretora da Université Ouvrière de Genève, por sua gentil e efetiva colaboração em permitir e facilitar nosso trabalho de coleta de dados nessa instituição.
Desde os tempos mais antigos, os deslocamentos das pessoas apresentamse como um processo humano e natural, mas foi a partir do desenvolvimento das relações capitalistas de produção, do desenvolvimento tecnológico, dos transportes e da globalização, somado às oportunidades econômicas tão desigualmente distribuídas em termos geográficos, que homens e mulheres passaram a deslocar-se de forma generalizada em busca de melhores salários e condições de vida.

Atualmente, assistimos ao aumento dos fluxos migratórios internacionais, que exibem soberbamente a sua complexidade, heterogeneidade e irreversibilidade, como toda marcha histórica, e são considerados como um dos maiores desafios sociais para os países envolvidos, tornando-se objeto 
de um número expressivo de contribuições importantes de carácter teórico e empírico.

A International Organization for Migration - IOM menciona que hoje há 214 milhões de migrantes no mundo, isto é, 3,2\% da população mundial, com alto impacto da imigração ilegal, e, daqueles, 94,5 milhões são mulheres, sendo a maioria dos deslocamentos realizada por motivos econômicos (OIM, 2010).

Em todos os países da Europa ocidental, registrou-se um aumento significativo da população imigrante na primeira década do milênio, que, apesar de algumas flutuações nos anos 2008/2009, alcançou, com a crise econômica, em 2010, 72,6 milhões de migrantes, cifra superior em 5,1 milhões à de 2005. Em termos absolutos, a Espanha foi o país que mais acolheu estrangeiros no ano 2006, alcançando um total de 840.800 pessoas, seguindo-se a Alemanha, com 661.900 pessoas, o Reino Unido, com 529.000, a França, com 182.400, e a Suíça, (que ocupa o quinto lugar), com um total de 127.600 pessoas (OIM, 2010).

A Suíça, que, durante muito tempo, foi considerada uma terra de emigração, visto que, no século XIX, milhares de suíços deixaram os vales alpinos e partiram para as Américas após a Segunda Guerra Mundial, revela a sua forte necessidade de mão de obra estrangeira para atender os seus programas de desenvolvimento e torna-se um país de grande atração para os migrantes. A diversificação de origem destes e as razões que os forçaram e continuam a forçá-los a deixar os seus países, sejam de ordem econômica, social ou política, têm contribuído não só para o enriquecimento econômico e cultural como também para o aumento populacional da Suíça (Franken, Coutinho, \& Ramos, 2007).

Nos últimos dez anos, o número de países de proveniência dos imigrantes que chegavam ao território suíço se ampliou, sendo incluídos de modo significativo os países de terceiro mundo. Destes, o Brasil apresenta-se com número expressivo; atualmente, o MRE/ BR avalia que cerca de 45 mil brasileiros residem na Suíça, vivendo a maioria em situação irregular, mas não especifica como foram feitos os cálculos. Entende-se, porém, que a maioria dos brasileiros que lá estão ingressaram no país na condição de turistas, e, depois dos 90 dias de permanência, entram para a clandestinidade (dados colhidos em visita ao Consulado Brasileiro em Genebra, em março de 2009).

Esses dados podem ser empiricamente identificados em uma visita à cidade de Genebra/Suíça, onde se observa a presença marcante de brasileiros nos mais variados ambientes públicos: praças, bares, supermercados, meios de transporte, etc.

Os poucos estudos disponíveis sobre os migrantes brasileiros indicam que, na maior parte dos casos, estavam desempregados ou em subempregos no Brasil, e, sobretudo, sem perspectivas de uma inserção com maior rendimento e status mais elevado na sociedade brasileira (Lopes, 2008).

Na realidade, são necessários estudos no Brasil que tratem dessa questão de forma mais aprofundada, ou seja, que, no lugar de reeditar dados estatísticos acerca da saída de brasileiros para o exterior, examinem a experiência concreta desses brasileiros nos países que os têm recebido.

\section{Migrações e processos de adaptação}

As migrações que se processam de uma cultura para outra ou de uma região do país para outra envolvem rupturas importantes no espaço e nas vivências do indivíduo; apresentam-se, necessariamente, como 
Segundo Berry

(1987), o modelo de aculturação acomoda quatro dimensões integração, assimilação, separação e marginalização - que surgem a partir dessas relações entre os indivíduos e que podem ser identificadas através de

duas perguntas particulares: i) Considero importante, para mim, a manutenção da minha identidade e características culturais? ii) Considero importante, para mim, a preservação da relação com outros grupos? uma transição social bem definida, o que implica, por regra, mudança de estatuto ou alteração no relacionamento com o meio envolvente, quer física, quer social ou jurídica. A migração implica a adaptação do indivíduo a uma cultura, língua e regras culturais de funcionamento diferente, a um novo meio, muitas vezes hostil, sendo necessário atravessar diferentes etapas e desenvolver estratégias de adaptação que the permitam resolver as dificuldades relacionadas com a condição de imigrante, de que resultam diferentes modalidades de aculturação.

A aculturação foi definida, pela primeira vez, em 1936, por três antropólogos, Redfield, Linton e Herskovitz, como o conjunto de transformações culturais resultantes dos contatos contínuos e diretos entre dois grupos culturais diferentes (Seabra, 2003), fenômeno psicossocial em que duas culturas exercem reciprocamente uma ação que vai resultar na mudança de cada uma delas por interpenetração de conteúdos culturais e de reinvenção, ou seja, de descobertas de novos conteúdos. Esse fenômeno caracteriza as mudanças que se processam na cultura de um grupo posto em contato com outro e compreende os fenômenos que resultam do contato direto e contínuo entre grupos de indivíduos de cultura diferente, com as subsequentes transformações nas formas das culturas originais de um ou dos dois grupos (Seabra, 2002).

Segundo Berry (1987), o modelo de aculturação acomoda quatro dimensões - integração, assimilação, separação e marginalização - que surgem a partir dessas relações entre os indivíduos e que podem ser identificadas através de duas perguntas particulares: i) Considero importante, para mim, a manutenção da minha identidade e características culturais? ii) Considero importante, para mim, a preservação da relação com outros grupos?
Com base nessas respostas, o modelo estabelece uma relação associativa com cada uma destas dimensões; quando positiva a resposta às duas questões, estamos diante de integração - manutenção da integridade cultural do grupo de pertença assim como de uma relação positiva para com a sociedade de acolhimento; quando negativa para a primeira e positiva para a segunda, estamos diante de assimilação - perda total da identidade cultural de origem e de escolha de interiorização das normas da sociedade de acolhimento (ou da sociedade dominante); quando positiva para a primeira e negativa para a segunda, estamos diante de separação - mantém e preserva a identidade cultural do grupo de pertença, mas opta por uma estratégia de rejeição das normas e dos valores da sociedade de acolhimento; quando negativa para as duas, estamos diante de marginalização - que se traduz pela perda total da relação da cultura de gênese e por uma não participação na sociedade de acolhimento. Caracteriza-se por sentimentos individuais de ansiedade, confusão, alienação, terminando o processo em uma situação de stress aculturativo. Embora esse modelo não possa ser aplicado na íntegra, nem ele constitua, em si, um método exato, permite tratar a questão do relacionamento entre o $\mathrm{Eu}$ e o Outro com bastante realismo de análise, sendo a pergunta sempre feita em relação ao indivíduo de um grupo minoritário (Berry, 1987).

A migração apresenta-se como um fenômeno social complexo, que envolve mudança não apenas de endereço, mas de toda uma série de contatos socioculturais do indivíduo, em todas as áreas de sua vida. As investigações e os indicadores de saúde disponíveis denotam que os migrantes apresentam maior vulnerabilidade a problemas de saúde (Lechner, 2007).

Os sentimentos oriundos da impossibilidade de possuir um só lugar de pertença, as 
condições sociais fragilizadoras, tais como a falta de documentação, a exploração no trabalho, a precariedade nas condições de habitação e a inadaptação linguística e cultural fazem com que a migração permaneça em suas vidas como uma ferida sempre aberta, podendo essas circunstâncias gerar problemas físicos, psicológicos e sociais que muitas vezes se associam a outros riscos inerentes ao próprio indivíduo e ao país de origem (Ramos, 2004, 2008; Achotegui, 2008; Franken, Coutinho, \& Ramos, 2007, 2009).

A população imigrante apresenta maior vulnerabilidade em questões de saúde, especialmente transtornos psicológicos com maior nível de ansiedade ou maior pessimismo em relação ao futuro, muitas vezes produzidos/agravados pela perda da rede social de apoio, pelo distanciamento devido ao não conhecimento da língua e pelas mudanças no seu estatuto social (Berra, Elorza Rocard, Bartomeu, Hausmann, SerraSutton, \& Rajmil, 2004).

À medida que o papel das migrações no mercado de trabalho europeu se torna mais relevante, a sua presença e a saúde dessa população é encarada como uma questão cada vez mais importante, não apenas do ponto de vista econômico mas também da perspectiva social.

Nas fontes pesquisadas para este estudo, não se encontraram dados sobre problemas de saúde mental entre imigrantes brasileiros residentes na cidade de Genebra/Suíça.

\section{Saúde mental, transtornos mentais comuns - TMC}

Entende-se que o conceito de saúde ou de enfermidade mental se apoia tanto nas expressões de problemas do tipo emocional, cognitivo e comportamental como em realidades simbólicas, construídas cultural e historicamente, na própria interação social (Lechner, 2007).

A diversidade de critérios utilizados para definir saúde mental associa-se ao problema da confusão entre saúde e doença, situações que não permitem definir uma delas como a ausência da outra, e soma-se aos diferentes paradigmas históricos conceituais e culturais que circulam nos vários campos teóricos metodológicos.

Nas análises das relações entre o fenômeno da migração e a saúde, quanto mais se procura compreender o universo complexo da migração, mais ganham destaque as questões relacionadas com a saúde, tanto física como mental.

A Organização Mundial de Saúde (OMS, 1975) define saúde mental como "o estado de bem-estar, no qual o indivíduo percebe as próprias habilidades, pode lidar com os estresses normais da vida, é capaz de trabalhar produtivamente e está apto a contribuir com sua comunidade". É mais do que ausência de doença mental.

Na literatura da Psicologia e da psiquiatria, tanto em estudos realizados no Brasil quanto no exterior, tem-se verificado a existência de uma associação entre o fenômeno da migração e o desenvolvimento de problemas psicopatológicos, ou seja, esses estudos (Ramos, 2008; Almeida Filho, \& Bastos, 1982) relatam que a migração, o estresse de aculturação, podem ter um impacto negativo na saúde mental dos indivíduos, sugerindo que as populações migrantes apresentam maior risco de desenvolver algum tipo de doença mental, como os transtornos mentais comuns (TMC). Essa expressão foi criada por Goldberg e Huxley (1992) para caracterizar sintomas como insônia, fadiga, irritabilidade, esquecimento, dificuldade de concentração e queixas somáticas, que designam situações de sofrimento mental. Pacientes com transtornos 
mentais comuns apresentam também taxas de mortalidade mais elevadas e sérios prejuízos nas funções sociais e física.

O estresse da aculturação envolve solidão, luta pela sobrevivência, pela alimentação, pela moradia, medo, sentimento de fracasso e desesperança quando as oportunidades não surgem. $\mathrm{O}$ imigrante torna-se candidato a padecer de quadros clínicos, o que compromete a sua saúde física e mental e constitui hoje um problema de saúde emergente nos países de acolhimento (Achotegui, 2008).

Em um estudo realizado em Barcelona sobre a população marginal, que incluía imigrantes econômicos, detectou-se que $48 \%$ dos homens imigrantes e $65,7 \%$ das mulheres apresentaram um estado de saúde regular, mau ou muito mau, resultado superior àquele obtido com a população geral da mesma localidade (Andrés, Barruti, Borrell, Calafell, Pasarín, \& Puigpinós, 2002).

No Brasil, Almeida Filho e Bastos, comparando prontuários psiquiátricos de pacientes femininas com síndrome depressiva, com dados de um inquérito de prevalência de doenças mentais realizado na cidade de Salvador, verificaram que o risco de a mulher migrante desenvolver tais sintomas era 2,5 vezes maior do que o da não migrante.

Em diferentes estudos (Ramos, 2008; Lechner, 2007; Achotegi, 2008) relativos aos transtornos mentais apresentados pelos imigrantes, destacam-se situações vivenciais que podem dar lugar a conflitos intensos e a complexos que influirão negativamente na saúde mental dessas populações, tais como as difíceis condições políticas e sociais, unidas estreitamente aos aspectos vinculados à migração ilegal, e as causas econômicas.

As sintomatologias somatoformes mais frequentes, no comprometimento da saúde mental dos imigrantes são: a fadiga, a cefaleia e as sintomatologias osteomusculares, e $76,7 \%$ dos migrantes com síndrome de Ulisses padeciam de cefaleia, quase sempre do tipo tensional, que estão associadas às preocupações recorrentes em que se encontram (Achotegui, 2008).

Contudo, não existe consenso quanto à relação direta da presença de doenças mentais em pessoas imigrantes especificamente. Achotegui (2008) e Almeida Filho e Bastos (1982) apontam maior concordância no que se refere a alguns quadros psiquiátricos específicos dos imigrantes, como a síndrome de Ulisses, o mutismo eletivo entre algumas crianças imigrantes, a psicose reativa breve em adultos imigrantes e os TMC.

Bermann, Collazos, Lahoz, Marxen, Qureshi e Sanjuán (2004) mostram, ao contrário, que há uma similaridade entre os problemas mentais observados na população imigrante e naquela não imigrante, e Baubet (2003) afirma que nem sempre os imigrantes, quando comparados com a população local, apresentam piores indicadores de patologias psíquicas.

O processo imigratório por si só não representa um fator de risco, mas revela que o impacto da migração na saúde e os determinantes presentes em cada etapa do processo imigratório variam não só com o tipo de imigração (legal/ilegal) como também com o conhecimento prévio dos serviços de saúde disponíveis no local de acolhimento e com o ambiente e a cultura de origem da pessoa que imigra, ou seja, os possíveis efeitos negativos sobre a saúde do imigrante dependeriam de quem, quando, onde e para onde imigra, levando-se em conta quais os parâmetros de saúde que serão avaliados e as representações de saúde/doença que traz essa população (Ramos, 2008; Franken et al., 2007). 
Risso e Böker (1992), no atendimento a imigrantes italianos na Suíça, chamam a atenção para a necessidade de os profissionais da saúde refletirem sobre sintoma e cultura, e expõem a necessidade de esses se precaverem quanto às tendências culturais na elaboração de diagnósticos de delírios e de doenças mentais, tendências essas estimuladas pelas tensões que provocam e pelo poder que se apresenta nas relações profissional/migrante.

Quando se pensa nos fatores de risco e na proteção para a saúde mental, deve-se compreender o que significam tais fatores nos contextos culturais específicos de cada indivíduo. Da igual forma, é necessário reconhecer o sintoma e a saúde mental como categorias que emergem da cultura ocidental e, especificamente, de um meio científico composto sobretudo pela biomedicina, pela Psicologia e pela Sociologia, que não são, portanto, categorias universais. Fatores de riscos e de proteção para a doença mental não podem ser vistos como universais, mas como emergentes da vida quotidiana coletiva e individual e das representações sociais dos atores sociais.

\section{Representações sociais}

A teoria das representações sociais é um dos modelos mais recentes dentro da Psicologia social, e, segundo Moscovici (2003), é fácil captá-las, mas não o seu conceito. Para esse autor, tanto o processo de busca de uma adaptação biopsicossocial como o saber comum da população, em geral, são a base para a criação de teorias que também procuram obter respostas para os acontecimentos quotidianos, passando por etapas de elaboração e de reformulação contínuas, transladadas pelos próprios sujeitos que experienciam a realidade.

Os conceitos criados a partir da vivência de uma pessoa, grupo ou comunidade que irão influenciar, quiçá determinar, o rol de comportamentos e de atitudes de um sujeito diante da sua realidade, por mais que sejam multiformes, possuem um aspecto social que depura a sua percepção, o parâmetro das suas representações simbólicas e sociais, aprendidas e passadas como saber históricoprático de indivíduo a indivíduo em seu desenvolvimento psicossocial (Moscovici, 2003).

Representações sociais são o conjunto de ideias compartilhadas por um grupo a propósito de um determinado fenômeno, e são sociais em dois sentidos: porque se referem a fenômenos sociais e porque nascem e são geradas na sociedade; são tipos de crenças paradigmáticas, organizações de conhecimento e de linguagem.

As representações sociais são também consideradas sistemas cognitivos com lógica e linguagem própria, não representando meras opiniões, são sistemas cognitivos que conformam diversificações do conhecimento, designam uma forma específica de conhecimento: "O saber do sentido comum", no qual o conteúdo representa uma forma particular de pensamento social (Moscovici \& Marková, 2003, p. 120).

Nessa direção, as representações sociais elaboram a construção da área social, isto é, ao agir, ao contar e/ou recontar uma história ou um fato, utilizam-se de conceitos que não são produzidos exclusivamente pelas suas ideias e imagens, mas por compartilhar o sentimento de pertença.

À luz dessa problemática anunciada e de extrema diversidade e complexidade, objetivou-se, no presente estudo, estimar a prevalência dos TMC e analisar as RS de imigrantes brasileiros (as) residentes na cidade de Genebra/Suíça a respeito dos construtos: imigração, imigrante, saúde mental e futuro. 


\section{Metodologia}

Este constitui um estudo de campo de abordagem quantitativa, realizado na cidade de Genebra/Suíça. A amostra foi do tipo não probabilístico por conveniência, e dela participaram 266 imigrantes entrevistados entre outubro de 2007 a outubro de 2009. Os critérios de elegibilidade dos indivíduos na constituição da amostra foram os seguintes: 1) aceitar participar do estudo, 2) ter idade mínima de dezoito anos e 3) viver na cidade de Genebra /Suíça há mais de um ano.

Os instrumentos utilizados foram um questionário, que continha questões biosociodemográficas, o Self-Reporting Questionnaire - SQR-20, criado em 1975 pela $\mathrm{WHO}$ e indicado como um método de baixo custo para o rastreamento psiquiátrico, e a entrevista semidirigida.

Para a execução da pesquisa, foram realizadas visitas a associações de imigrantes e a instituições religiosas e de ensino ${ }^{1} \mathrm{com}$ a finalidade de ter acesso a imigrantes brasileiros que aceitassem participar da pesquisa. Após a apresentação e o estabelecimento do contato com os imigrantes, foram discutidas questões sobre a participação e o consentimento informado, dadas informações relevantes sobre o estudo, explicados os objetivos e garantida à confidencialidade de suas respostas, e, finalmente, foi esclarecido que os resultados não trariam prejuízos as suas atividades e que seriam analisados em seu conjunto. Sempre no final de cada entrevista, era solicitado aos respondentes que indicassem colegas imigrantes com a finalidade de serem posteriormente contatados para participar da pesquisa.

Como procedimentos para o processamento dos dados, utilizou-se o Pacote Estatístico para Ciências Sociais (SPSS for windows 19.0), empregando a estatística descritiva e inferencial, e, para o processamento dos dados colhidos através do Self Report Questionnaire-20 (SQR-20), acompanhando as orientações de trabalhos mais recentes
(Gonçalves, Stein, \& Kapczinski, 2008), considerou-se como indicativo da presença de transtorno mental comum (TMC) o participante que respondesse afirmativamente a 7/8 questões do instrumento para o sexo masculino e feminino, respectivamente. Para a realização das entrevistas semidirigidas, utilizou-se o critério de saturação proposto por Sá (1998), alcançando um total de 20 participantes - os conteúdos colhidos foram analisados pelo método de análise de conteúdo (Bardin 1997/2002).

Este estudo foi realizado considerando os aspectos éticos pertinentes a pesquisas que envolvem seres humanos. Para trabalhar com atores sociais imigrantes, o projeto foi submetido à avaliação do Conselho Nacional de Ética em Pesquisa (CONEP - Brasília-DF/ $\mathrm{BR})$, e recebeu aprovação através do parecer no 570/2007, em 11 de julho de 2007.

\section{Resultados}

Da totalidade da amostra $(n=266)$, observamos que $57,5 \%$ são do sexo feminino, $64,2 \%$ declararam viver sozinhos, $79,7 \%$ estão na faixa etária de 18 a 39 anos, 47,7\% possuem o ensino médio completo, $39,8 \%$ vivem em Genebra entre 1 a 3 anos, 74,8\% estão em condição irregular para viver e trabalhar no país de acolhimento, 85.3\% não possuíam domínio da língua francesa antes da imigração, atualmente, $45.1 \%$ trabalham em serviços domésticos e $72,9 \%$ utilizam os períodos da manhã ou da tarde e parte da noite em suas atividades laborais.

Os resultados obtidos a partir do instrumento Scrining Self-Reporting Questionnaire - SQR20 demonstraram que, do total da amostra, $37,2 \%$ apresentaram a probabilidade de presença de transtornos não psicóticos - TMC.

A probabilidade de presença de transtornos não psicóticos entre os participantes, segundo as variáveis: sexo, tempo de imigração, tipo 
de imigração, será apresentada na Tabela ํo 1, a seguir:

Tabela 1 . Valores descritivos em relação às variáveis, sexo, tempo de imigração e tipo de imigração dos participantes e a positividade ou negatividade na probabilidade de presença de transtornos não psicóticos e indices do Chi-Square

\begin{tabular}{|c|c|c|c|c|c|c|c|c|c|}
\hline & \multicolumn{7}{|c|}{ SQR 20} & \multirow[t]{3}{*}{$X^{2}$} & \multirow{3}{*}{$\begin{array}{l}\text { Niv. } \\
\text { Sig }\end{array}$} \\
\hline & & \multicolumn{2}{|c|}{ SIM } & \multicolumn{2}{|c|}{ NÃO } & \multirow[t]{2}{*}{ Total } & \multirow[t]{2}{*}{ Total \% } & & \\
\hline & & Freq. & $\%$ & Freq. & $\%$ & & & & \\
\hline \multirow[t]{2}{*}{ Sexo } & Feminino & 62 & 62,6 & 91 & 54,5 & 153 & 57,5 & \multirow{3}{*}{1,68} & \multirow{3}{*}{0,20} \\
\hline & Masculino & 37 & 37,4 & 76 & 45,5 & 113 & 42,5 & & \\
\hline Total & & 99 & 100 & 167 & 100 & 266 & 100 & & \\
\hline \multirow[t]{3}{*}{ Tempo } & 1 a 3 a & 60 & 60,6 & 46 & 27,6 & 106 & 39,8 & \multirow{4}{*}{28.8} & \multirow{4}{*}{0,001} \\
\hline & De 3 a 5 a & 20 & 20,2 & 71 & 42,5 & 91 & 26,0 & & \\
\hline & + de 5 anos & 19 & 19,2 & 50 & 29,9 & 69 & 34,2 & & \\
\hline Total & & 99 & 100 & 167 & 100 & 266 & 100 & & \\
\hline \multirow{4}{*}{$\begin{array}{l}\text { Tipo de } \\
\text { imigração }\end{array}$} & Regularizada & 23 & 23,2 & 44 & 26,3 & 67 & 25,2 & \multirow{5}{*}{0,32} & \multirow{5}{*}{0,06} \\
\hline & & & & & & & & & \\
\hline & Não & 76 & 76,8 & 123 & 73,7 & 199 & 74,8 & & \\
\hline & Regul & & & & & & & & \\
\hline Total & & 99 & 100 & 167 & 100 & 266 & 100 & & \\
\hline \multicolumn{2}{|c|}{ total da amostra } & 99 & 37,2 & 167 & 62,8 & 266 & 100 & & \\
\hline
\end{tabular}

A variável sexo, em que $62,6 \%$ das mulheres apresentaram a probabilidade de presença de transtornos não psicóticos, não esteve associada ao TMC ( $p>0,05)$, como se pode observar na Tabela ํㅜ 1, acima:

Observa-se que, dos 99 participantes que apresentaram a probabilidade da presença dos transtornos não psicóticos ou TMC, 60,6\% possuem tempo de imigração de 1 a 3 anos, 20,2\% de 3 anos e 1 mês a 5 anos, e 19,2\% possuem tempo de imigração além de 5 anos. Somente essa variável esteve associada ao TMC $(p=0,001)$.

Em relação à variável tipo de imigração, dos 99 participantes que apresentaram a probabilidade de transtornos mentais comuns, verifica-se que 76,8\% estão com tipo de imigração não legalizada, isto é, não possuem autorização para viver e trabalhar no país de acolhimento, como pode ser observado na Tabela no 1 , acima.

Utilizando-se o critério de saturação (Sá, 1998) quanto ao instrumento de entrevista semidirigida, alcançamos um total de 20 participantes que já haviam oferecido dados nos demais instrumentos e aceitavam participar da entrevista, que durava em média 40 minutos. Esta foi realizada no local de aplicação dos demais instrumentos ou marcava-se outro dia e local de acordo com a conveniência dos participantes, em lugares públicos como cafés, shoppings, parques. Dos 20 participantes, 12 são de nacionalidade brasileira; 9 são do sexo masculino, e todos $(N=20 ; 100 \%)$ na faixa etária de 18 a 39 anos; Quanto à variável tipo de imigração, todos 
os participantes portugueses $(n=8)$ e somente 2 dos participantes brasileiros estavam em situação regular para viver e trabalhar no país de acolhimento; 6 dos entrevistados apresentaram a probabilidade de TMC, sendo que, destes, 4 eram do sexo feminino. O material colhido foi transcrito e seus conteúdos receberam uma leitura flutuante, em torno das quatro classes temáticas, a saber: imigração, imigrante, saúde mental e futuro, que correspondem aos grandes temas abordados nas entrevistas; encontrou-se um total de 515 unidades temáticas, que foram agrupadas na categoria concepção. Para Bardin (1997/2002), categorias são formas gerais de conceito ou de pensamento, podem ser capazes de sintetizar o saber e são consideradas rubricas ou classes que reúnem elementos (unidades de registro) com características comuns.

Da classe temática imigração, a categoria empírica concepção emergiu com 73 unidades temáticas, que foram agrupadas em quatro subcategorias, a saber: sentimentos de ruptura, que reuniam $20,5 \%$ das evocações, sentimentos ambivalentes, com 15,2\%; o papel social de menor valia, que contribuiu com $21,9 \%$ das evocações, e a subcategoria aquisições, que concentrava $42,4 \%$ do total das unidades temáticas da categoria concepção.

\section{a) A imigração como sentimento de} ruptura - como demonstram os recortes das entrevistas a seguir: “(...) Imigração é deixar sua família (...), é separação (...), é deixar seu país (...), é separar-se dos seus (...), é sofrer, calado, a dor da saudade (...), é deixar tudo que você ama e conhece e partir para um lugar desconhecido (...)".

\section{b) A imigração como sentimentos} ambivalentes - para esses atores sociais, a imigração possui, concomitantemente, dois valores diferentes, como se pode observar nos recortes abaixo:
“(...) Triste, mas necessário para melhorar de vida (...), satisfação por fazer novas conquistas, mas muito doloroso, porque estamos longe das pessoas que amamos (...)".

\section{c) A concepção da imigração como um papel} social de menor valia - nessa subcategoria, ancoraram o fenômeno da imigração como um papel social de menor valia para os autóctones, como se demonstra a seguir: “(...) É ser explorado (...), é trabalhar mais e ganhar menos (...), sem papéis, você não tem direito a nada, não é nada para a sociedade deles (...), só serve para limpeza, nada mais (...), é humilhação (...), é sentir na pele o preconceito (...), é ser indesejado (...)".

d) A imigração como aquisição - a imigração é representada como aquisição de valores materiais, cognitivos e culturais através das unidades temáticas expressas pelos brasileiros, como pode ser observada nos recortes apresentados logo a seguir: “(...) É ter dinheiro (...), ter trabalho (...), é conseguir sua casa no Brasil (...), é ter dinheiro para melhorar sua vida e da sua família (...), é ter novas oportunidades em tudo (...) e ter condições de adquirir o que não podes no teu país (...), ter trabalho (...)".

Da classe temática imigrante, emergiu a categoria empírica concepção, com 85 unidades temáticas, que foram agrupadas em quatro subcategorias, a saber: valores pessoais positivos, que concentrava $22,3 \%$ do total das unidades temáticas: valores sociais negativos, que representava 28,2\% das evocações; aspectos psicoafetivos, que contribuíram com 22,3\% das evocações, e a subcategoria aquisições, com $27,0 \%$ das unidades temáticas.

\section{a) O imigrante como alguém que possui} valores pessoais positivos - nessa subcategoria, representaram o imigrante como uma pessoa que possui valores pessoais positivos, como o demonstram, abaixo, os recortes das entrevistas: “(...) É forte (...), é 
corajoso (...), alguém determinado (...), é um guerreiro (...), é batalhador (...), desbravador (...), tem garra (...), é um vencedor (...), tem coragem (...), é uma pessoa forte (...)".

b) $O$ imigrante como alguém que recebe valores sociais negativos - nessa subcategoria, a concepção de imigrante foi ancorada em valores sociais negativos, como pode ser visto, a seguir, nos recortes das entrevistas: “(...) Um invasor, (...) sem papéis, é uma pessoa acuada, (...) é ser visto como um aventureiro, (...) é ser olhado com desconfiança, (...) é ter menor valor, é ser visto como mentiroso, (...) um retirante (...)".

\section{c) O imigrante representado através} de aspectos psicoafetivos - a categoria concepção, da classe temática imigrante, fez emergir unidades temáticas ancoradas em uma subcategoria que foi denominada aspectos psicoafetivos, que podem ser observados nos recortes das entrevistas apresentados logo a seguir: “(...) É sentir muita dor da saudade, (...) é pessoa que conhece o desespero, (...) sente falta de apoio, (...) é um pesadelo, (...) estresse, (...) é sentir saudade da sua terra e saber que você não cabe mais lá, (...) é dissimulador do sofrimento, (...) ansiedade".

\section{d) O imigrante como alguém que faz} aquisições - nessa subcategoria, a concepção da classe temática imigrante foi ancorada em aquisições e representou $27,0 \%$ das unidades temáticas evocadas, como pode ser visto, a seguir, nos extratos das entrevistas: "(...) É poder comprar sua casa, (...) é conseguir seu melhor carro, (...) é ter trabalho, (...) é ter uma bela casa no Brasil, (...) é ter trabalho e dinheiro para melhorar a vida dos filhos, (...) e trabalhar para alcançar seus objetivos (...)".

Da classe temática saúde mental, emergiu a categoria empírica concepção, com 62 unidades temáticas, que foram agrupadas em seis subcategorias, a saber: a subcategoria características pessoais positivas, que contribuiu com $20,9 \%$ do total das unidades temáticas, a subcategoria impossibilidade, que colaborou com $14,5 \%$ do total das evocações dessa classe temática, a subcategoria aspectos cognitivos, que concorreu com 12,9\% de unidades temáticas, a subcategoria aspectos sociais, cuja contribuição foi de 20,9\%, a subcategoria aspectos psicológicos/espirituais, que participou com $11,3 \%$ das unidades temáticas, e a subcategoria aspectos materiais, que cooperou com $19,3 \%$ do total da categoria concepção de saúde mental.

\section{a) A saúde mental como aspecto pessoal} positivo - como demonstram, abaixo, os recortes das entrevistas: “(...) É pensar positivo, (...) ter bom humor, (...) ter sentimento de acolhimento, (...) ser desinibido, (...) ter bons pensamentos, (...) espírito elevado, (...) é ser despreocupado (...)" .

\section{b) A saúde mental como impossibilidade -} como demonstram as verbalizações a seguir: “(...) Aqui? É impossível ter saúde mental, (...) saúde mental como imigrante é impossível, (...) para esta situação aqui, sem papéis, é impossível ter saúde mental, (...) na solidão em que vivemos, aqui, é impossível ter saúde mental (...)".

\section{c) A saúde mental como aspecto cognitivo}

- nessa subcategoria, a concepção de saúde mental foi ancorada em aspectos cognitivos. Compreendem-se as evocações a partir dos recortes das entrevistas que apresentaremos a seguir: “(...) É estar preparado para a vida, (...) é ter sabedoria, (...) é ter instrução, (...) ter uma boa mentalidade, (...) é ler bons livros, (...) viajar e adquirir conhecimentos, (...) é realizar seus estudos, (...) ter boa formação (...)".

\section{d) A categoria concepção da saúde mental} como aspecto social - como pode ser observado nos recortes das entrevistas que se seguem: “(...) Ajudar os outros, (...) estar em companhia da família e dos amigos, (...) ter 
uma comunidade que te conheça e te estime, (...) estar perto dos seus, (...) ter bons amigos, (...) escolher, (...) escolher bons amigos, (...) relacionar-se bem com as pessoas (...)".

e) A concepção da saúde mental como aspecto psicológico e espiritual - conforme se observa nos recortes das entrevistas a seguir: “(...) Saúde mental é felicidade, (...) é bem-estar, (...) é dignidade, (...) equilíbrio, (...) é ter fé em Deus, (...) ter paz, (...) é saber amar (...)".

\section{f) A saúde mental como aspecto material}

- entre os participantes desta pesquisa, da categoria concepção de saúde mental, emergiu a subcategoria aspectos materiais, que pode ser observada nos recortes das entrevistas apresentadas, a seguir: “(...) Saúde mental é ter dinheiro para atender o que necessitas, (...) é conseguir pagar as contas no final do mês, (...) é ter sua casa, (...) é poder ter o seu carro, (...) ter conforto em sua casa, (...) é ter garantido o atendimento das suas necessidades (...)".

A classe temática futuro fez emergir entre os participantes a categoria concepção, com 51 unidades, que foram organizadas em quatro subcategorias, a saber: aspectos biológicos, com $15,6 \%$ do total dos elementos, aspectos psicológicos/espirituais, com o contributo de $21,5 \%$, aspectos sociais, formado com $41,1 \%$ das unidades temáticas, e 21,5\% para a subcategoria aspectos materiais, conforme é apresentado na Tabela no 26 e nos recortes das entrevistas.

a) $\mathrm{O}$ futuro como aspectos biológicos conforme os recortes que seguem: "(...) É ter uma boa saúde, (...) em primeiro lugar saúde, (...) ter energia para tocar a vida, (...) manter a sua saúde, (...) ter uma vida saudável, (...) para chegarmos a ele, necessitamos ter saúde, ( ..) estar forte (...)".

b) O futuro como aspectos psicológicos e espirituais - a seguir, apresentam-se os estratos das entrevistas, demonstrando a formação dessa subcategoria: “(...) Futuro é só alegrias, ( ..) é amor, (...) é confiança, (...) é felicidade, (...) é Deus, ele é que sabe, (...) futuro é fé é crença, (...) é incertezas, (...) é medo, (...) é esperança, (...) é ser reconhecido como um cidadão (...)".

c) O futuro como aspectos sociais e sentimentos de retorno - as evocações que formaram essa subcategoria: “(...) Futuro é poder ajudar os outros, (...) é ter os amigos ao seu dispor, (...) é voltar para o seu país e poder estar com a sua família, (...) é estar legalizado na sociedade onde trabalho, (...) é Brasil (...)".

\section{d) $\mathbf{O}$ futuro como aspectos materiais - essa} subcategoria foi formada a partir da categoria concepção, e foi organizada com as seguintes evocações: “ (...) É ter dinheiro, (...) é ter uma bela morada, (...) é ter a sua casa, (...) é poder ter o seu carro, (...) é ter garantida sua habitação, (...) é viver bem, (...) ter um bom automóvel, (...) um belo carro (...)".

\section{Análise dos resultados}

Ao analisar as variáveis biosociodemográficas do total da amostra $(N=266)$, percebe-se que o perfil desses participantes concorda com os dados do relatório de 2009 do Office Fédéral de la Statistique (OFS) e com os estudos de Franken et al. $(2007,2009)$ ao revelarem uma crescente efeminização das migrações, e mostram uma população jovem em idade laboral, que sempre se apresentou como a principal protagonista do processo imigratório internacional de modo geral, e do suíço, em particular, e um nível de escolaridade maior do que o das populações imigrantes de anos anteriores, como as das décadas de 60 a 80 do século passado.

Segundo Seabra (2003), o conjunto das mudanças econômicas, sociais e culturais vem afetando as relações de gênero e levando 
a um aumento da migração feminina, de maneira tal que, em muitos casos, esse contingente supera o masculino nas migrações. Igualmente Criado (2000), ao referir-se a algumas características dos movimentos migratórios, aponta o aumento do número de mulheres como imigrantes autônomas e da imigração irregular, e afirma que esses movimentos afetam não somente a área econômica mas também a social, política e cultural dos países envolvidos.

Do total dos participantes, a maioria possui imigração do tipo não documentada $(74,8 \%)$, imigraram sozinhos $(74,4 \%)$, não possuíam o domínio da língua francesa antes da imigração $(85,3 \%)$ e executam trabalhos essencialmente domésticos $(45,1 \%)$, isentos de qualquer possibilidade de segurança social, cujo pagamento é exclusivamente um salário muito abaixo do mínimo exigido no país. Os índices de trabalho na indústria e no comércio apresentaram percentagens de $13,2 \%$ e $17,3 \%$, respectivamente. Sabese, porém, que um grande número desses participantes, embora empregue a sua força laboral nesses setores da economia, encontrase vinculado de fato, mas não de direito, pois exercem uma atividade clandestina (no negro) - sem documentação ou sem registro como trabalhador, principalmente quando se trata de serviços de restaurantes ou de limpeza.

O perfil desses participantes corrobora os estudos de Gonçalves relativos ao número crescente de imigrantes irregulares em vários países de todo o mundo. Ele observa que: “(...) o sujeito é recebido como trabalhador, mas recusado como cidadão. Os governos dos países receptores querem trabalhadores para os serviços mais sujos, pesados e mal pagos, mas não abrem oportunidades para novos cidadãos" (2005, p. 15).

Marginalmente incluídos no mercado de trabalho, sem papéis (pois não são cidadãos europeus), sentem-se forçados a oferecer a sua força laboral em postos funcionais que estão aquém da sua escolaridade como forma de garantir a sua sobrevivência no país de acolhimento. O seu nível de escolaridade dá-lhes condições intelectuais e motivação para iniciarem um caminho de novas aquisições, novos conhecimentos e diferentes habilidades, mas são, muitas vezes, impedidos não somente por essa condição de ilegalidade como também por falta de condições físicas, já que esmorecem após um intenso e longo período de atividade laboral muitas vezes superior a 8 horas diária - $(72,9 \%$ relataram trabalhar os dois períodos diários e parte da noite).

Os trabalhadores nativos não estão preparados para ser pouco remunerados em trabalhos duros que requeiram trabalho manual pesado e de longas horas. Os empregadores encorajam, portanto, a migração de outros países de menor desenvolvimento para encarregá-los de serviços subalternos e menos remunerados. Entretanto, tais empregadores não incentivam os imigrantes a permanecerem e os mantêm desprovidos dos benefícios sociais e de cidadania nos países receptores, situação essa identificada no grupo de participantes brasileiros (Berra et al., 2004; Gonçalves, 2005).

Os resultados obtidos através do instrumento Self-Reporting Questionnaire - SQR-20, que identifica a probabilidade de presença de transtornos não psicóticos ou TMC, permitiram verificar um alto percentual de participantes que apresentaram a probabilidade de presença de transtornos não psicóticos ( $\mathrm{N}=266 ; 37,2 \%$; Tabela 1), dados esses que estão de acordo com os estudos realizados por Ramos (2008), Achotegi (2008) e Franken et al. (2007), que afirmam que o processo migratório traz alterações e sofrimentos nos diferentes âmbitos da vida do imigrante.

Alguns autores (Gonçalves, Stein, \& Kapczinski, 
2008), bem como parte significativa dos textos que lhes servem de referência, relatam a influência da variável sexo em relação ao comprometimento da saúde mental, apontando percentagens mais altas para as mulheres de todas as categorias diagnosticadas. Nesse estudo, embora a frequência da probabilidade de TMC tenha sido mais alta para as mulheres, não há diferenças estatisticamente significativas associadas à variável sexo.

A partir dos resultados expostos na Tabela 1 , pode-se inferir que imigrantes com menor tempo de imigração (de 1 a 3 anos, $39,8 \%$ ), e que estão vivenciando todas as assimilações e acomodações do processo de aculturação apresentam maior probabilidade de transtornos não psicóticos. Tais resultados fazem lembrar Goldberg e Huxley (1992), que caracterizaram esses transtornos através de sintomas como insônia, fadiga, irritabilidade, esquecimento, dificuldade de concentração e queixas somáticas, que designam situações de sofrimento mental.

Os imigrantes abandonam a família, os amigos e os locais conhecidos e seguros para enfrentar uma nova cultura e uma nova língua, além da desvalorização da sua capacidade laboral, e, embora possuam qualificações, estas não são absorvidas pelo mercado de trabalho, pois a maioria, com escolaridade de nível médio completo ou superior, trabalha em serviços domésticos.

Sendo assim, parece correto afirmar que, para alcançar um nível maior de adaptação ao local de acolhimento, ou a modalidade de aculturação chamada por Berry (1987) de integração, o imigrante, além dos recursos individuais e sociais, necessitará de um espaço temporal suficientemente capaz (e essa suficiência será delimitada pelos diferentes matizes que constituíram o processo imigratório) de reparar as arestas intrínsecas dessa fricção cultural, demonstrando, assim, que o tempo de imigração é uma variável a ser considerada nos estudos sobre o fenômeno imigratório.

Através da análise de conteúdo pode-se concluir que, para esses participantes, a experiência da imigração põe em jogo uma questão essencial que é o sentimento de pertença. Assim, "deixar a sua família (...), separação (...), ir para longe da sua terra (...), deixar tudo o que você ama e conhece (...)" são palavras e expressões que formam parte das associações dos imigrantes na hora de narrar as suas vivências. A imigração, para eles, associa-se à ruptura com o espaço de vida de origem, que inclui: relações familiares, laborais e sociais, a separação de suas tradições, da língua e dos costumes culturalmente reconhecidos. Efetivamente, vivenciam sentimentos que mobilizam nostalgias e tristezas quando somados à necessidade de adaptar-se rapidamente ao local de acolhimento, de enfrentar não apenas uma nova cultura e língua, mas também a hostilidade que todo local desconhecido impõe aos novos forasteiros e que pode desencadear sofrimentos emocionais.

Essas dificuldades reaparecem nas representações da classe temática futuro quando são alicerçadas em condições biológicas básicas como a saúde, demonstrando que a saúde aparece como primordial em qualquer entendimento do porvir. Nessa trajetória, necessitam de fé, de prender-se à espiritualidade para fortalecer sentimentos de perseverança e de continuidade em sua sobrevivência no local de acolhimento. Assim, enfrentar "(...) incertezas, medo, ser reconhecido como cidadão (...)", unidades temáticas da subcategoria aspectos psicológicos e espirituais, permitem-nos inferir que esses participantes, por vivenciarem, na sua maioria, um tipo de imigração não documentada, representam o tempo futuro com a incerteza, o medo e o desejo de serem reconhecidos como cidadãos no 
local de acolhimento, o que a situação de ilegalidade vivida hoje não lhes permite. Assim, ter amigos, voltar para a família, estar legalizado na sociedade de acolhimento e conviver melhor com as pessoas são representações marcadas por vivências de ilegalidade, solidão e sofrimento. Pode-se, ainda, concluir que essas representações de futuro concordam com os estudos de Sayad (2000) e De Biaggi e Paiva (2004) quando afirmam que a ideia de retorno está intrinsecamente circunscrita à denominação, enquanto a ideia de emigração-imigração e a do retorno é, naturalmente, o desejo e o sonho acalentado por todos os imigrantes.

Pode-se compreender que o processo imigratório envolve múltiplos fatores, que poderão facilitar ou dificultar a adaptação na sociedade de acolhimento, tais como: condições sociais fragilizadoras, preconceito, exploração, ilegalidade, mudança de estatuto da pessoa, dificuldades na comunicação e obter moradia, que geram maior vulnerabilidade em questões de saúde, especialmente transtornos psicológicos.

Explica-se o sentido das evocações simbólicas através das interações e práticas sociais dos participantes ao realizarem a representação do ser imigrante organizadas nas subcategorias valores pessoais positivos como uma pessoa forte, corajosa, um guerreiro, mas que é visto pelos autóctones com valores sociais negativos, tais como: um invasor, um aventureiro, é ser olhado com desconfiança, sem papéis, é uma pessoa acuada. Esses conteúdos permitem-nos verificar que, no universo social, esses participantes trabalham e contribuem para o desenvolvimento social do local de acolhimento e de seu país de origem, o que é confirmado através do expressivo envio de remessas (Ratha, 2006). Porém vivenciam, na sua maioria $(26,2 \%$ das evocações), sentimentos de subalternidade social. Essa análise é sustentada pelos estudos de Couceiro (2004), que observa que certos segmentos do mercado de trabalho se tornaram constitutivos da condição do imigrante laboral e indissociáveis dos imigrantes no imaginário popular, pois são os empregos mais mal pagos e menos qualificados. Essa situação, que confirma a condição de subalternidade social, reduz o imigrante à mera condição de força de trabalho, esgota os seus corpos no processo de acumulação de capital e mostra que nunca chegarão a fazer, definitivamente, parte do país onde despendem essa força.

Esse mesmo autor (Couceiro, 2004), em sua publicação A Vida Doméstica nos Alpes, destaca que, no século XXI, existe uma nova forma de escravidão, que consiste na exploração da mão de obra de estrangeiros clandestinos. Muitos destes, não vendo outro meio de se libertarem da ameaça de expulsão, sujeitam-se à aviltante situação de terem de aceitar baixos salários e de continuarem na sua situação de ilegais, e passam a viver e a trabalhar sob o estigma do medo e da exploração.

Na condição irregular para viver e trabalhar no local de acolhimento ( $n=199 ; 74,8 \%$ ), vamos encontrar situações comuns de estresse, como: (i) a falta de segurança física que é motivada pela situação de ilegalidade, com o consequente risco de serem identificados pelas autoridades e verem morrer o sonho de uma imigração bem sucedida, (ii) a condição financeira, pois recebem salários aquém do mínimo exigido, já que são explorados por possuírem a condição de ilegais, (iii) o horário de trabalho, que compreende períodos longos e trabalhos duros e incertos (na maioria domésticos e de construção civil), além de muito tempo gasto na atividade laboral, pouco remunerada e sem segurança social nem perspectivas de acesso a novos conhecimentos ou cursos de qualificação, que exigem disponibilidade de tempo, de recursos econômicos e de cidadania. Essas situações de estresse podem explicar o índice de 37,2\% 
do total de brasileiros que apresentaram a probabilidade de presença de transtornos mentais comuns.

Igualmente, as suas representações sociais refletem as suas vivências ao ancorarem a concepção de saúde mental em uma situação de impossibilidade para eles: "Aqui? É impossível ter saúde mental, saúde mental como imigrante é impossível; para esta situação aqui, sem papéis, é impossível ter saúde mental na solidão em que vivemos". Mas também em aspectos pessoais positivos, os participantes concretizaram a saúde mental em: "pensamentos positivos, dignidade, desinibido, serenidade, tranquilidade, paciência". Pode-se entender que, frente às situações adversas do processo imigratório, a saúde mental implicará a competência de desenvolver, aplicar e fortalecer as características pessoais positivas. Irremediavelmente, a situação de ilegalidade apresenta-se como feridas sociais toleradas que exigem investimentos de toda ordem por parte do ser imigrante, (emocionais, econômicos, administrativos) para, no final de sua longa e dura jornada de trabalho chegar à casa triunfante por ter driblado, por mais um dia, a possibilidade da sua identificação/deportação, mesmo que esse triunfo seja alcançado com déficits para a sua saúde através do stress que se cronifica dia após dia.

$\mathrm{Na}$ subcategoria aspectos cognitivos, a concepção de saúde mental emerge materializada nas expressões: "estar preparado para a vida, ter sabedoria, instrução, ser inteligente". Os aspectos cognitivos fundamentam as representações, demonstrando que buscar novos conhecimentos, ter boa formação, estudos e sabedoria participam do significado de saúde mental. Esses participantes, na maioria jovens e com nível de escolaridade mediano ou mais, associam a saúde mental ao crescimento intelectual.
Na subcategoria aspectos sociais, a família, os bons amigos, os contatos com outras pessoas emergiram como parte da concepção de saúde mental. Para esses participantes, ter amigos, estar perto dos familiares, ter boa convivência com todos é uma forma de conceituar a saúde mental. Assentam o conceito de saúde mental em aspectos da vida social real. Essa análise se fortalece com os resultados da associação dos TMC, com os participantes com tempo de migração entre 1 a 3 anos (Tabela1; $x^{2}=28,8 p=0,001$ ). Essa variável associada ao TMC confirma que o período de aculturação, quando o estresse invade diferentes áreas da vida do ser migrante (o afastamento da família, sua chegada a um novo meio, dificuldades em encontrar trabalho e moradia, comunicar-se, etc.), é a razão do déficit em sua saúde mental.

A cultura, as trocas simbólicas e o processo de construção e reconstrução do quotidiano conduzem cada indivíduo à organização de uma realidade que tem como base um imaginário coletivo diverso em cada tempo e espaço que se transforma em um imaginário individual, sem deixar, no entanto, de ser uma expressão do que é coletivo. Moscovici (1978) explica que esse imaginário constitui um conhecimento construído que irá reger a forma como os indivíduos representam o mundo e conduzem as suas ações. Cada indivíduo constrói e utiliza uma representação social de um objeto, possivelmente relacionada com o grupo social ao qual pertence.

\section{Conclusão}

As migrações humanas, de modo geral, e as internacionais, em particular, são parte de dinâmicas socioeconômicas globais multifacetadas e multicausais que apresentam consideráveis prevalências para as causas econômicas laborais. Envolvendo rupturas importantes no espaço e nas vivências do indivíduo, apresentam-se, necessariamente, como uma transição social bem definida; 
implicando, por regra, mudança de estatuto ou alteração no relacionamento com o meio envolvente, quer seja físico, social ou jurídico. Essas rupturas, juntamente às dificuldades que se apresentam no processo de aculturação (como ilegalidade, falta de conhecimento da língua utilizada no país de acolhimento, trabalho, moradia e costumes), tornam-se fatores estressores que comprometem a saúde física, mental e social do imigrante no local de acolhimento.

Neste estudo, verificou-se que a variável tempo de imigração recebeu peso significativo nos índices de probabilidade de presença de TMC e que as referências teóricas sobre saúde mental e aculturação apresentadas comungam uma forte reação à ênfase dada a essa variável. Igualmente, as subcategorias mais positivas - aquisições, aspectos materiais, características pessoais positivas, aspectos cognitivos e aspectos sociais - emergiram, em maioria (8:12), entre participantes com maior tempo de imigração e/ou que não apresentaram a probabilidade de presença de TMC, o que permite assinalar que RS mais positivas emergem entre aqueles que já vivenciaram os primeiros anos de aculturação e que não apresentam a probabilidade da presença de TMC ou que essa probabilidade foi solucionada com o decorrer do seu tempo de vivência no local de acolhimento.

Entendeu-se, igualmente, que o desafio que aproxima os pesquisadores envolvidos com o fenômeno migratório internacional é a necessidade e a dificuldade desse estudo, cujo objeto é multifatorial, complexo e irreversível nesses tempos de globalização; entretanto, o estudo é indispensável nas diferentes esferas da vida dos imigrantes, entre elas, a da saúde mental, para que essa compreensão se amplie e propicie subsídios que possam auxiliar a formular políticas de admissão que contemplem o trânsito e a permanência de pessoas em outros países, garantindo suas potencialidades em diferentes esferas da vida.

\section{leda Franken}

Doutorado em Psicologia Clínica e da Saúde pela Universidade Aberta de Lisboa, Portugal. Professora Adjunta da Universidade Federal da Paraíba- PB -Brasil.

E-mail: iedafranken@gmail.com

\section{Maria da Penha de Lima Coutinho}

Doutorado em Psicologia Clínica pela Universidade de São Paulo, Professor adjunto IV da Universidade Federal da Paraíba, PB - Brasil.

E-mail:mplcoutinho@gmail.com

\section{Maria Natália Pereira Ramos}

Doutorada em Psicologia Clínica Intercultural pela Universidade Rene Descartes. Professora associada de nomeação definitiva a tempo integral, Universidade Aberta de Lisboa, Lisboa - Portugal.

E-mail: nataliapramos@gmail.com

Endereço para envio de correspondência:

Rua Juíz Agrícola Montenegro, 105 apto. 1604 Bairro Miramar, João Pessoa - PB - Brasil. CEP: 58032-210

Recebido 12/6/2011, 1a Reformulação 26/9/2011, Aprovado 15/10/2011. 


\section{Referências}

Achotegui, J. (2008, março). Migración y crisis: El síndrome del inmigrante con estrés crónico y multiple (síndrome de Ulises). Avances en Salud Mental Relacional, 7(1), 1-22.

Almeida Filho, N., \& Bastos, S. B. (1982). Estudo caso controle da associação entre migração e desordens depressivas em mulheres. Jornal Brasileiro de Psiquiatria, 31, 25-29.

Almeida-Filho, N. (2000). What does the word 'health' mean? Cadernos de Saúde Pública, 16(2), 300-301.

Andrés, J., Barruti, M., Borrell, C., Calafell, J., Pasarín, M., \& Puigpinós, R. (2002). Salud y marginación social. Revista de Documentación Social, 127, 97-123

Bardin, L. (2002). Análise de conteúdo. Lisboa: Edições 75. (Trabalho original publicado em 1997).

Baubet, M. R. M. (2003). Syndrome méditerranéen, sinistrose... II n'y a pas de pathologie spécifique de la migration. In M.R.M. Baubet, Psychiatrie et migrations. (pp 93-112). Paris : Masson.

Bermann S., Collazos F., Lahoz S., Marxen E., Qureshi A., \& Sanjuán L. (2004, 10-13 de novembro). Aspectos epidemiológicos y hermenéuticos de la atención en salud mental a los inmigrantes: Retos para los profesionales. Comunicación del 4 Congreso sobre la inmigración en España. Ciudadanía y participación. Girona.

Berra, S., Elorza Rocard, J. M., Bartomeu, N., Hausmann, S., Serra-Sutton, V., \& Rajmil, L. (2004). Necessitats en salud i utilització dels serveis sanitaris en la població immigrant a Catalunya; revisió exhaustiva de la literatura científica. In Anales de Medicina. Barcelona: Agència d' avaluació de Tecnología i Recerca Mèdiques.

Berry, J. W. (1987). Acculturation and mental health. In P. Dasen, J. Berry, \& N. Sartorius, (Eds.). Health and cross-cultural research. (pp. 45-64). London: Oxford University Press.

Couceiro, B. A vida de doméstica nos Alpes. Swiss info. 06/12/2004. Recuperado em maio, 2008, de: http://www. athoele.com/database/index.php?option $=$ com_content\&tas $k=$ view\&id $=460 \&$ Itemid $=45$

Criado, M. J. (2000). Vieja y nueva migración. Rasgos, supuestos y evidencias. Revista Internacional de Sociología (RIS), 26, 159-183.

DeBiaggi, S. D., \& Paiva, G. J. (Orgs.), Psicologia, e/ imigração e cultura. São Paulo: Casa do Psicólogo.

Franken, I., Coutinho, M. P. L., \& Ramos, N. (2007). Migração internacional, qualidade de vida e representação social. In E. C. Krutzen, \& S. B. Vieira, (Orgs)., Psicologia social, clínica e da saúde mental. João Pessoa, PB: Editora Universitária. UFPB.

Franken, I., Coutinho, M. P. L., \& Ramos, N. (2009). Migração e qualidade de vida: um estudo psicossocial com brasileiros migrantes. Estudos de Psicologia, 26(4), 419-27.

Goldberg, D. P., \& Huxley, P. (1992). Common mental disorders - A biosocial model. London: Routledge.

Gonçalves, D. M., Stein, A. T., \& Kapczinski, F. (2008). Avaliação de desempenho do Self-Reporting Questionnaire como instrumento de rastreamento psiquiátrico: um estudo comparativo com o Structured Clinical Interview for DSM-
IV-TR. Cadernos de Saúde Pública, 24, 380-390.

Gonçalves, A. (2005, 05-06 de outubro). A mobilidade humana e a globalização: fenomenologia e desafios. In 1 Encontro Nacional das Pastorais da Mobilidade Humana. Brasília, DF. Recuperado em 12 março, 2007 de http://www.migrante.org. br/textoseartigos.htm

International Organization for Migration (2010). État de la migration dans le monde 2010 - l'avenir des migrations : Renforcer les capacités face aux changements. Genéva: Auteur

Lechener, E. (2007). Imigração e saúde mental. Migrações. Migração e Saúde. (Revista do Observatório da Imigração, ACIDI, 1, Alto Comissariado para a Imigração e Diálogo Intercultural). Lisboa, Portugal.

Lopes, L. C. (2008). Brasileiros em Montreal. Recuperado em 23 setembro de 2009 de: http://www.ucm.es/info/especulo/ numero39/.htm

Moscovici, S. (2003). Representações sociais : investigações em psicologia social (P. Guareschi, trad.). Petrópolis, RJ: Vozes.

Moscovici, S., \& Marková, I. (2003). La presentación de las representaciones sociales: diálogo con Serge Moscovici. In J. A. Castorina, (Org.), Representaciones sociales. Problemas teóricos y conocimientos infantiles. (pp. 9-27). Barcelona: Gedisa.

Office Fédéral de la Statistic. OFS. (2009). Annuaire Statistique de la Suisse - Switzerland. Ed. I'Office Fédéral de la Statistique. Neuchâtel, Suíça.

Ramos, N. (2004). Psicologia clínica e da saúde. Lisboa: Universidade Aberta.

Ramos, N. (2008). Migração, aculturação e saúde. In N. Ramos, (Org.). Saúde, migração e interculturalidade: perspectivas teóricas e práticas (pp. 45-96). João Pessoa, PB: Editora Universitária. UFPB.

Ratha, D. (2006). Economic implications of remmitances and migrations. London: World Bank.

Risso, M., \& Böker, W. (1992). Sortlégio e delirio. Psicopatologia delle migrazioni in prospettiva transculturale. Napoli: Liguori.

Sayad, A. (2000, janeiro). O retorno: elemento constitutivo da condição do migrante. Travessia, 13(Esp.), 7-32.

Seabra, P. J. B. (2003). Percursos migratórios de imigrantes brasileiros e do leste europeu em Portugal. Dissertação de mestrado em Relações Interculturais. Porto: Universidade Aberta.

World Health Organization Expert Committee on Mental Health. (OMS). (1975). Organization of mental health services in developing countries: Sixteenth report of the WHO Expert Committee on Mental Health. Geneva: World Health Organization. (Technical Reports Series, 564). 